
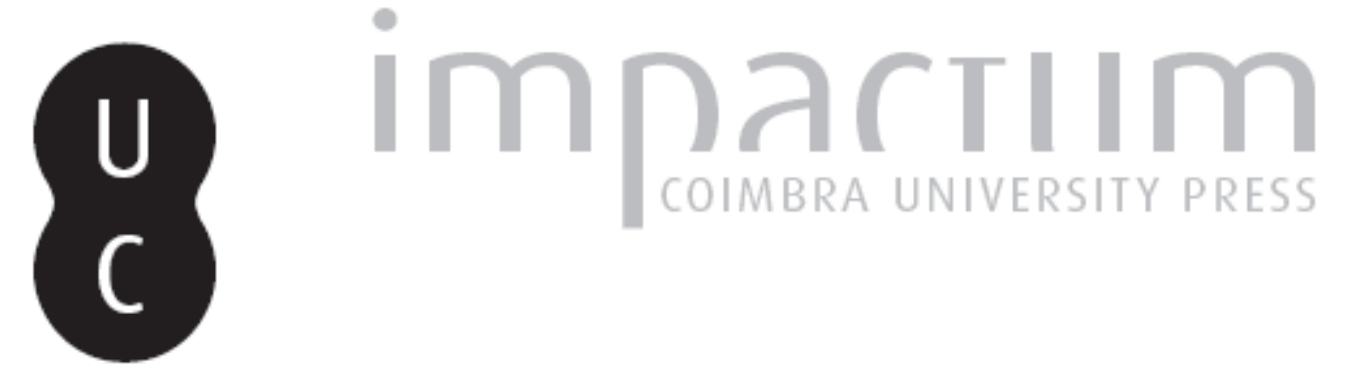

\title{
La gestión integrada de las zonas costeras en el marco de la política ambiental y marítima de la Unión Europea
}

Autor(es): $\quad$ Sanz Larruga, Francisco Javier

\section{Publicado por: CEDOUA}

URL persistente:

URI:http://hdl.handle.net/10316.2/8842

DOI:

http://dx.doi.org/10.14195/2182-2387_23_1

Accessed : $\quad$ 26-Apr-2023 16:01:17

A navegação consulta e descarregamento dos títulos inseridos nas Bibliotecas Digitais UC Digitalis, UC Pombalina e UC Impactum, pressupõem a aceitação plena e sem reservas dos Termos e Condições de Uso destas Bibliotecas Digitais, disponíveis em https://digitalis.uc.pt/pt-pt/termos.

Conforme exposto nos referidos Termos e Condições de Uso, o descarregamento de títulos de acesso restrito requer uma licença válida de autorização devendo o utilizador aceder ao(s) documento(s) a partir de um endereço de IP da instituição detentora da supramencionada licença.

Ao utilizador é apenas permitido o descarregamento para uso pessoal, pelo que o emprego do(s) título(s) descarregado(s) para outro fim, designadamente comercial, carece de autorização do respetivo autor ou editor da obra.

Na medida em que todas as obras da UC Digitalis se encontram protegidas pelo Código do Direito de Autor e Direitos Conexos e demais legislação aplicável, toda a cópia, parcial ou total, deste documento, nos casos em que é legalmente admitida, deverá conter ou fazer-se acompanhar por este aviso.

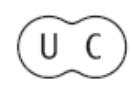


Doutrina

N.․․ 23 _Ano XII_1. 09

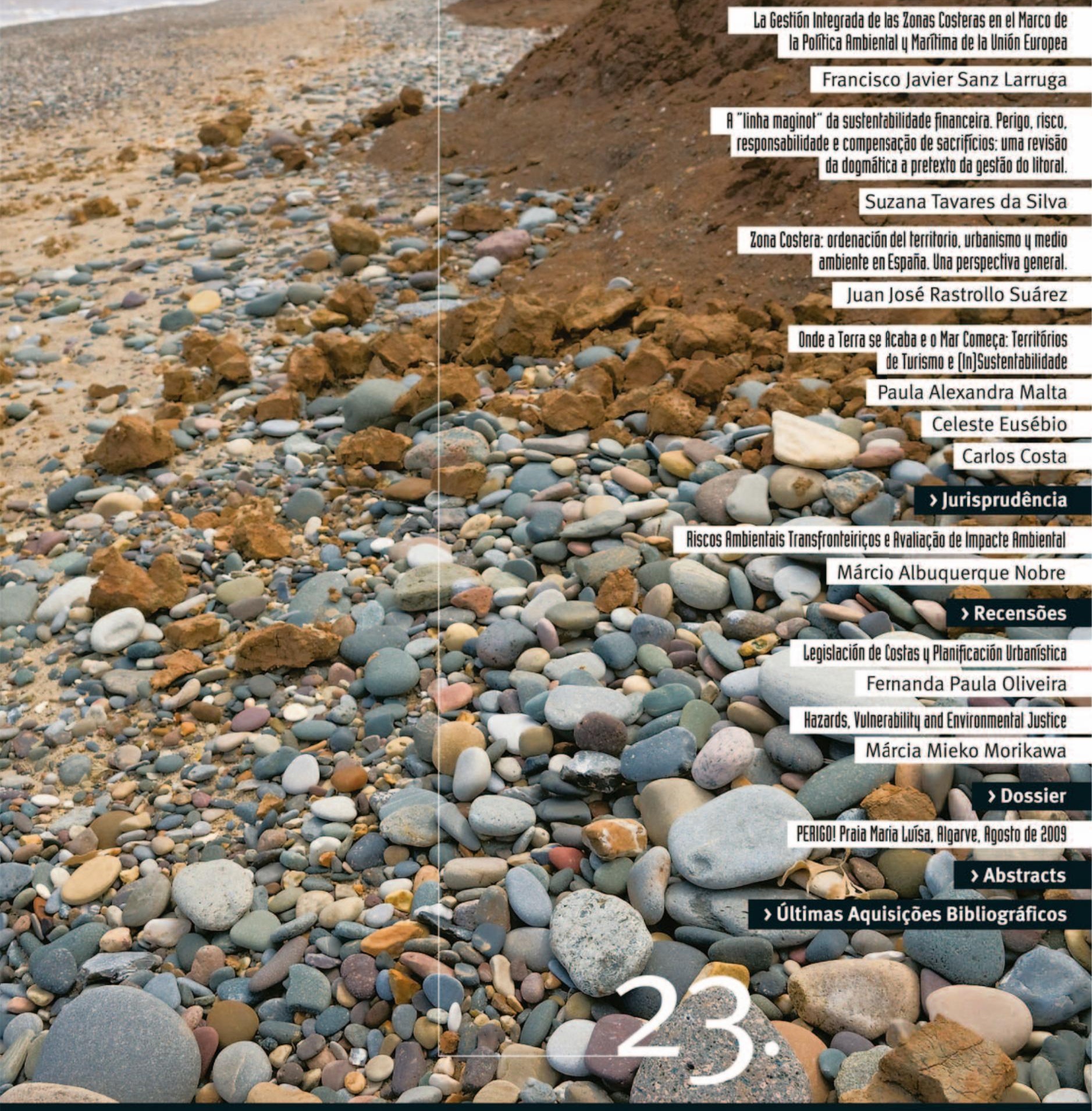

Revista do Centro de Estudos de Direito do Ordenamento, do Urbanismo e do Ambiente Urbanism, Territorial Order and Environment Studies Center Law Review 


\title{
La Gestión Integrada de las Zonas Costeras en el Marco de la Política Ambiental y Marítima de la Unión Europea
}

\begin{abstract}
A gestão integrada das zonas costeiras adquiriu um particular impulso a partir da conferência do Rio de Janeiro sobre o Meio Ambiente e Desenvolvimento Sustentável, de 1992, cuja agenda XXI contempla como uma das acções prioritárias a da "ordenação integrada e sustentável das zonas costeira e zonas marítimas".

0 presente texto incide sobre a "Estratégia Comunitária para a Gestão Integrada das Zonas Costeiras da Europa" e sobre a recomendação 2002/413/CE relativa à aplicação da gestão integrada das zonas costeiras na Europa, fornecendo uma visão global das questões que as mesmas colocam.
\end{abstract}

\section{Introducción}

Durante los últimos decenios la ordenación y gestión de las zonas costeras ha recibido el influjo de una nueva corriente doctrinal que suele denominarse "gestión integrada de las zonas costeras" (conocida también en inglés bajo las siglas IZCM: Integrated Coastal Zone Management $)^{1}$ y que fue especialmente difundida a partir de la aprobación en Estados Unidos de la Ley federal sobre "gestión de las zonas costeras" de 1972 (Coastal Zone Management Act) $)^{2}$.

\footnotetext{
${ }^{1}$ La bibliografía sobre la IZCM es particularmente abundante en el mundo anglosajón. A modo de ejemplo, citamos las obras de: BEATLEY, T., BROWER, T., et al.: An Introduction to Coastal Zone Management. Washington, D.C, Island Press, 1994; CICAN-SAIN, B.: Integrated Coastal and Ocean Management: Concepts and Practices. Washington, D.C, Island Press, 1998; CLARK, J.: Coastal Zone Management, Handbook. New York, Lewis Publishers, 1995; GESAMP: The Contributions of Science to Coastal Zone Management. Rep. Stud. GESAMP, IMO/FAO/UNESCO-IOC/WMO/WHO/IAEA/ UN/UNEP Joint Group of Experts on the Scientific Aspects of Marine Environmental Protection. 61 (1996): 66; KAY, R. and ALDER J.: Coastal Planning and Management. E \& FN Spon, 1999; PERNETTA, J., and ELDER, D.: Cross-sectoral, Integrated Coastal Planning: Guidelines and Principles for Coastal Area Development. Gland, Switzerland, IUCN, 1993; PILARCYZK, K.W. (ed): Coastal Protection. Balkema, Rotterdam, The Netherlands, 1990; TURNER, R.K., ADGER, W.N., LORENZONI, I.: Towards Integrated Modelling and Analysis in Coastal Zones: Principles and Practices. LOICZ Reports and Studies No. 11, IGBP/LOICZ, Texel, The Netherlands, 1998; VALLEGA, A.: Fundamentals of Integrated Coastal Management. Kluwer Academic Publishers, 1999. En España, el Profesor BARRAGÁN MUÑOZ de la Universidad de Cadiz, ha sido uno de los más principales difusores y tratadistas de estas nuevas corrientes científicas y metodológicas sobre el litoral; cfr. sus trabajos monográficos: Ordenación, planificación y gestión del espacio litoral, Oikos-tau, Barcelona, 1993; Medio ambiente y desarrollo en áreas litorales: introducción a la planificación y gestión integradas, Servicio de Publicaciones de la Universidad de Cádiz, Cádiz, 2003; Las áreas litorales de España. Del análisis geográfico a la gestión integrada. Barcelona, Ariel, Barcelona, 2004; Política y gestión de áreas litorales en España, La gestión de áreas litorales en España y Latinoamérica, Universidad de Cádiz, Cádiz, 2005. Por lo que se refiere a Portugal queremos destacar los trabajos de ALVES, M.F.L.: Gestão sustetável das Zonas Costeiras. Contributos para um modelo de avaliaçao, Tesis doctoral em Ciências Aplicadas al Ambiente, Universidade de Aveiro, 2005; MARTINS, F.M.: Políticas de Planeamento, Ordenamento e Gestao Costeira. Contributo para uma discussao metodológica, Tesis doctoral. Departamento de Ambiente e Ordenamento. Universidade de Aveiro, Aveiro, 1997; y VELOSO GOMES, F. (COORD.): Bases para a Estratégica da Gestão Integradsa da Zona Costeira Nacional, Projecto de Relatório do Grupo de Trabalho, Ministerio de Ambiente, do Ordenamento do Territorio e do Desenvolvimiento Regional, 23 de janeiro de 2006, 2006. ${ }^{2}$ Sobre esta Ley pionera cfr. el reciente trabajo de: HERRERA XIMENEZ, M. D.: "La gestión costera en los Estados Unidos: Coastal Zone Management Act, 1972 y la estructura del programa asociado Coastal Zone Management Program", en SANZ LARRUGA, F.J. (Dir.) y GARCÍA PÉREZ, M. (Coord.): Estudios sobre la ordenación, planificación y gestión de
} 
La gestión integrada de las zonas costeras (GIZC) adquirió un mayor impulso a partir de la "Conferencia de Río de Janeiro sobre Medio Ambiente y Desarrollo Sostenible" de 1992 cuya Agenda XXI contempla como una de las acciones prioritarias la de la "ordenación integrada y sostenible de las zonas costeras y zonas marítimas" (Capítulo 17²). Además, otros organismos internacionales como la OCDE ha venido recomendado desde mediados de los años setenta de pasado siglo la conveniencia de promover modelos de gestión integrada del litoral ${ }^{3}$.

En el ámbito europeo la GIZC ha ido cobrando fuerza creciente desde los años ochenta del pasado siglo, si bien a través de declaraciones programáticas (soft law) como la "Carta Europea de Litoral” de 1981, las Recomendaciones del Consejo de Europa (por ejemplo, la Recomendación 29/1973 sobre Protección de Zonas Costeras o sus más recientes iniciativas de la "Ley Modelo de Gestión Sostenible de la Zonas Costeras” y el "Código de Conducta europeo de las Zonas Costeras" de 1999) y la promoción por la Comunidad Europea, a partir de mediados de los años noventa del siglo pasado, de una "Estrategia Comunitaria para la Gestión Integrada de las Zonas Costeras en Europa". Sobre dicha Estrategia -que se inicia en 1995- y sobre la Recomendación 2002/413/CE sobre la aplicación de la gestión integrada de las zonas costeras en Europa, que es su principal manifestación jurídica, trata este trabajo que, a su vez, en Portugal se ha plasmado recientemente en la "Estratégia Nacional da Gestão Integrada da Zona Costeira" aprobada por la Resolução del Presidente del Conselho de Ministros no 82/2009, de 20 de agosto de $2009^{4}$.

La aplicación de la Recomendación 2002/413/CE en los diferentes países costeros de la Unión Europea, pese a sus indudables limitaciones, va a incidir, a mi juicio, muy positivamente, en sus Ordenamientos jurídicos respectivos, abriendo nuevas perspectivas para los gestores públicos y otros actores sociales que, sin duda, acabarán redundando en un mejory más acertado diseño de las políticas sobre ordenación, planificación y gestión de nuestras zonas costeras.

\section{La recomendación comunitaria de 2002 sobre la aplicación de la gestión integrada de las zonas costeras en europa ${ }^{5}$.}

\section{Orígenes y fundamento.}

“Las regiones costeras de la Unión Europea están sometidas a una presión constante. Hoy en día, prácticamente la mitad de la población de la Unión reside en una franja de 50 Kms en

litoral: Hacia un modelo integrado y sostenible, Fundación Pedro Barrié de la Maza y Observatorio del Litoral de la Universidad de A Coruña, A Coruña, 2009. También puede consultarse el trabajo de: VILLANUEVA CUEVAS, A.: La regulación jurídica del litoral costero en Estados Unidos, Editorial Alfonsipolis, C.B. 2006.

${ }^{3}$ Cfr. la publicación de la ORGANIZACIÓN DE COOPERACIÓN Y DESARROLLO ECONÓMICOS: Gestión de zonas costeras. Políticas integradas, OCDE-Ediciones MundiPrensa, Madrid, 1995.

${ }^{4}$ Diário da República, $1^{a}$ série -no 174 - 8 de septiembro de 2009, pp. 6056-6088. El procedimiento de elaboración de este Estrategia se inició con la elaboración en 2006 del documento "Bases para a estratégia de gestão integrada da zona costeira nacional”, sometido a información pública en 2007 mediante su publicación por el Ministério do Ambiente, do Ordenamento do Território e do Desenvolvimento Regional. En su elaboración intervino principalmente el "Instituto da Áuga" tomando como referencia estudios anteriores y a través de la consulta a diversas entidades públicas y privadas así como a la comunidad científica. Sobre la base del marco normativo vigente -y en coherencia con las diversas Estrategias, Políticas y programas nacionales sobre medio ambiente y ordenación del territorio-, esta nueva Estrategia sobre el litoral portugués define una "visión" para un periodo de veinte años estructurada en cuatro objetivos de carácter general (o transversales) y cuatro objetivos temáticos quye, a su vez, se concretan en veinte medidas. Sobre el régimen jurídico del litoral en Portugal que constituye el marco regulatorio de su nueva Estregia costera cfr. el reciente trabajo de ALVES CORREIA, F.: "Líneas generales de la ordenación y gestión de la zona costera en Portugal”, en SANZ LARRUGA, F.J. (Dir.) y GARCÍA PÉREZ, M. (Coord.): Estudios sobre la ordenación, planificación y gestión de litoral: Hacia un modelo integrado y sostenible, cit. pp. 69-80.

${ }^{5}$ Un exhaustivo estudio de esta Recomendación y su preparación puede encontrarse en mi trabajo: "La Unión Europea y la estrategia comunitaria sobre gestión integrada de las zonas costeras”, en SANZ LARRUGA, F.J. (Dir.) y 


\section{$\operatorname{RerCED\varrho ̈̈UA~}$}

torno a la costa; los recursos de las zonas costeras, además, generan buena parte de la riqueza económica de la Unión. Las industrias de los sectores pesqueros, del transporte marítimo y del turismo compiten por encontrar un espacio vital en los $89.000 \mathrm{kms}$ estimados del litoral europeo, a lo largo del cual se encuentran, también, algunos de los hábitats naturales más frágiles y valiosos de Europa"

Desde mediados de los años setenta las Instituciones comunitarias se mostraron interesadas en abordar los problemas de gestión y ordenación que se estaban produciendo en las zonas costeras. Hasta llegar a la Recomendación 2002/413/CE sobre la aplicación de la gestión integrada de las zonas costeras en Europa"7 , aprobada por el Parlamento Europeo y el Consejo el 30 de mayo de 2002, se ha tenido que recorrer un largo camino que tiene como hitos fundamentales:

1‥- la "Carta Europea del Litoral”, aprobada -con base en las Recomendaciones del Consejo de Europa sobre la protección de las costas y otras Declaraciones de poderes locales y regionales- por la "Conferencia Plenaria de Regiones Periféricas Marítimas de la Comunidad Económica Europea” (que agrupaba a setenta regiones del litoral comunitario), celebrada en Knania (Creta) en octubre de $1981^{8}$.

2ํ.- la inclusión en los Tratados consitutivos de las Comunidades Europeas, en virtud del "Acta Única Europea” de 1986, de la política comunitaria relativa al medio ambiente y su reforzamiento con la reforma introducida por el Tratado de Maastricht de 1992. A partir de estas reformas se pusieron en marcha iniciativas para promover, sobre la base de la política ambiental, la gestión integrada de las zonas costeras ${ }^{9}$.

GARCÍA PÉREZ, M. (Coord.): Estudios sobre la ordenación, planificación y gestión de litoral: Hacia un modelo integrado y sostenible, Fundación Pedro Barrié de la Maza y Observatorio del Litoral de la Universidad de A Coruña, A Coruña, 2009, pp. 29-54.

${ }^{6}$ COMISIÓN EUROPEA: La Unión Europea apuesta por las zonas costeras, Comunidades Europeas, Luxemburgo, 2001, p. 3. Esta publicación está disponible en castellano en la web:

http://ec.europa.eu/environment/iczm/pubs.htm (última consulta: 20 de mayo de 2010).

Otros datos -extraídos del folleto informativo de la Comisión Europea Hechos y cifras claves sobre el mar (2006). que ponen de la relieve la importancia de las regiones costeras son los siguientes:

- Se estima que entre el 3 y el $5 \%$ del producto interno bruto (PIB) de Europa es generado por industrias y servicios relacionados con el mar, sin incluir el valor de las materias primas, como el petróleo, la pesca o el gas.

- Casi el $90 \%$ del comercio exterior de la UE y más del $40 \%$ de su comercio interno se transporta por mar.

- 3500 millones de toneladas de carga por año y 350 millones de pasajeros pasan por los 1200 puertos marítimos europeos.

- El liderazgo europeo en materia de navegación es indiscutible ya que cuenta el $40 \%$ de la flota mundial.

- La acuicultura representa el 19 \% de la producción pesquera total de la Unión. Para 2030, la acuicultura suministrará más de la mitad del pescado consumido en todo el mundo.

- En las regiones marítimas se genera más del 40 \% del producto interno bruto (PIB) de Europa.

- Europa tiene entre 8 y 10 millones de pescadores marítimos que practican la pesca recreativa o deportiva y con una industria relacionada que factura de 8 a 10 mil millones de euros.

${ }^{7}$ DOCE no L 148, de 6 de junio de 2002. Su texto puede consultarse en la dirección siguiente:

http://eur-lex.europa.eu/LexUriServ/LexUriServ.do?uri=CELEX:32002H0413:EN:NOT (última consulta: 20 de mayo de 2010).

${ }^{8}$ Cfr. PÉREZ CONEJO, L.: Las costas marítimas: régimen jurídico y competencias administrativas, Comares, Granada, 1999, pp. 50-59; CALERO RODRIGUEZ, J. R.: Régimen jurídico de las costas españolas, Aranzadi, Pamplona, 1995, pp. 56-59; y MORENO CANOVÉS, A.: Régimen jurídico del litoral, Tecnos, Madrid, 199o, pp. 85-87. El texto de este documento puede consultarse en la recopilación elaborada por FUENTES BODELÓN, F.: Calidad de vida, medio ambiente y ordenación del territorio. Textos internacionales, I, CEOTMA-CIFCA, Madrid, 1982, pp. 211-217. La Carta Europea de Litoral recibió el apoyo del Parlamento Europeo en una Resolución de 18 de junio de 1982, invitando a la Comisión a respaldar las acciones previstas en el campo de los conocimientos, de la planificación y del control. ${ }^{9}$ Así, pueden citarse, a modo de ejemplo, los siguientes documentos institucionales:

- La Comunicación COM(86) 571 de 30 de octubre de 1986, relativa a "la ordenación integrada de las zonas costeras: su función en la política comunitaria de medio ambiente". 


\section{$\operatorname{RerCEDöUA~}$

$3^{0}$.- la puesta en marcha en 1996 y desarrollo del "Programa de demostración de la Comisión Europea sobre la ordenación integrada de las zonas costeras” hasta $1999^{10}$, cuya experiencia fue plasmada en dos importantes documentos estratégicos de la Comisión: el denominado "Hacia una estrategia europea para la gestión integrada de las zonas costeras: principios generales y opciones políticas"11, y el que lleva por título: “Lecciones del programa de demostración de la Comisión Europea sobre la gestión integrada de las zonas costeras" ${ }^{12}$.

$4^{\circ}$.- La propuesta de Recomendación sobre la aplicación de la gestión integrada de las zonas costeras articulada por la Comisión sobre la base de sus documentos aprobados en septiembre de $2000^{13}$.

\section{Estudio sistemático de la Recomendación}

La Recomendación se compone de seis Capítulo relativos a "Un planeamiento estratégico" $\left(1^{\circ}\right)$, los “Principios" ( $\left.2^{\circ}\right)$, los “Inventarios Nacionales” $\left(3^{\circ}\right)$, las “Estrategias Nacionales” $\left(4^{\circ}\right)$, la "Cooperación" ( $5^{\circ}$ ) y los "Informes y la revisión" (6ํ), que pasamos a exponer seguidamente.

\section{A. El planteamiento estratégico y sus bases fundamentales}

La Recomendación comienza destacando que el “planeamiento estratégico" para la GIZC debe tener en cuenta las estrategias que sobre el medio ambiente y el desarrollo sostenible ha aprobado la Comunidad Europea; en particular:

- la "Estrategia europea para un desarrollo sostenible", aprobada por la Comisión Europea el 15 de mayo de 2001 y presentada en el Consejo Europeo de Gotemburgo de junio de $2001^{14}$.

- El "Sexto Programa de acción en materia de medio ambiente", titulado “Medio ambiente 2010: el futuro está en nuestras manos".

- La Resolución del Consejo de Ministros de 25 de febrero de 1992, sobre la "gestión integrada de las zonas costeras".

- La Resolución del Consejo de 6 de mayo de 1994, relativa a "una estrategia comunitaria de gestión integrada de la zona costera".

Asimismo, los Programas de Acción en materia de medio ambiente de la Comisión Europea reflejaron desde entonces esta prioridad (cfr. el 5ำ y el 6을 Programas).

${ }^{10} \mathrm{Cfr}$. los documentos:

- La Comunicación de la Comisión al Consejo y al Parlamento Europeo sobre "la gestión integrada de las zonas costeras" (COM(95) 511 final, de 31 de octubre de 1995)

- La Comunicación de la Comisión Europea (COM(97) 744 final, de 12 de enero de 1998

${ }^{11}$ Oficina de Publicaciones de la Comunidad Europea, Luxemburgo, 1999.

${ }^{12}$ Oficina de Publicaciones de la Comunidad Europea, Luxemburgo, 1999. Uno de los documentos preparatorios de carácter jurídico fue el elaborado por J. GIBSON: "Legal and regulatory bodies: appropiateness to Integrated Coastal Zone Management" y hecho público por la Comisión Europea en octubre de 1999. En este documento se barajaba la posibilidad de que la iniciativa comunitaria sobre el litoral europeo se plasmara en una Directiva.

${ }^{13}$ Cfr. Los documentos de la Comisión COM(2000) 547 final sobre la GIZC: "una estrategia para Europa", de 27 de septiembre de 2000, dirigido por al Consejo y Parlamento europeos (presenta una serie de conclusiones y recomendaciones que constituyen una estrategia de la Unión Europea para una GIZC, que se basa en los resultados del Programa de Demostración) y el COM(2000) 545 final sobre la aplicación de la GIZC en Europa, de 8 de septiembre, sobre la propuesta de recomendación propiamente dicha.

${ }^{14}$ Esta estrategia tiene su origen en la invitación cursada, en diciembre de 1999, por el Consejo Europeo de Helsinki a la Comisión Europea a "elaborar una propuesta de estrategia a largo plazo que integre políticas de desarrollo sostenible desde los puntos de vista económico, social y ecológico". Incluye una serie de medidas concretas para que la Unión Europea pueda mejorar su proceso de toma de decisiones en cuanto a la coherencia y la visión a largo plazo, así como determinados objetivos considerados de primera línea y las medidas necesarias para alcanzarlos. 


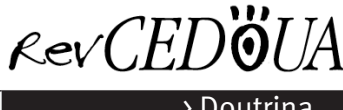

Las "bases" en la que se fundamenta el planeamiento estratégico que deberían adoptar los Estados miembros son las siguientes (Capítulo $\left.{ }^{0}{ }^{\circ}\right)$ :

a) la protección del medio ambiente costero, formulado en términos de ecosistemas y capaz de preservar la integridad y funcionamiento de los mismos, así como la gestión sostenible de los recursos naturales de los componentes tanto marinos como terrestres de las zonas costeras;

b) el reconocimiento de la amenaza que representa para las zonas costeras el cambio climático y los peligros que conlleva el aumento del nivel del mary la violencia y frecuencia crecientes de los temporales;

c) unas medidas de protección de las costas que sean adecuadas y ecológicamente responsables, incluida la protección de los núcleos de población costeros y su o patrimonio cultural;

d) unas posibilidades económicas y laborales sostenibles;

e) un sistema social y cultural operativo en las comunidades locales;

f) las zonas adecuadas accesibles para el público, tanto con fines estéticos como recreativos;

g) en el caso de las zonas costeras aisladas, el mantenimiento o el fomento de su cohesión;

h) una mejor coordinación de las actuaciones de todas las autoridades participantes, tanto en el mar como en tierra, en la gestión de la interacción mar-tierra.

\section{B. Principios y medidas para la aplicación de la Estrategia comunitaria}

En cuanto a los "principios" y "medidas" que deberían seguir las estrategias nacionales sobre gestión integrada de las zonas costeras, teniendo en cuenta las "buenas prácticas" definidas en el "programa de demostración" de la Comisión y otros similares, el Capítulo $2^{\circ}$ enumera los siguientes:

a) una perspectiva amplia y global (temática y geográfica) que tome en cuenta la interdependencia y disparidad de los sistemas naturales y las actividades humanas que tengan incidencias en las zonas costeras;

b) una perspectiva a largo plazo que tenga en cuenta el principio de cautela y las necesidades de las generaciones actuales y futuras;

c) una gestión modulada en un proceso gradual que facilite las adaptaciones según surjan problemas y evolucionen los conocimientos. Ello exige una sólida base científica relativa a la evolución de las zonas costeras;

d) las características locales y la gran diversidad de las zonas costeras de Europa, de forma que pueda responderse a sus necesidades prácticas con soluciones específicas y medidas flexibles; 


\section{$\operatorname{RerCEDöUA~}$}

e) un trabajo en sintonía con los procesos naturales y que respete la capacidad de carga de los ecosistemas, con lo cual las actividades humanas serán más respetuosas con el medio ambiente, más responsables socialmente y racionales, desde el punto de vista económico, a largo plazo;

f) la participación de todas las partes interesadas (interlocutores económicos y sociales, organizaciones representativas de los residentes de las zonas costeras, las organizaciones no gubernamentales y el sector empresarial) en el proceso de gestión, por ejemplo mediante acuerdos y según el principio de la responsabilidad compartida;

g) el apoyo y la participación de todas las instancias administrativas competentes a escala nacional, regional y local, entre las cuales convendrá establecer o mantener los vínculos adecuados para mejorar la coordinación de las distintas políticas existentes. Según corresponda, se debería proceder a establecer asociaciones con las autoridades regionales y locales o entre las mismas;

h) el recurso a una combinación de instrumentos destinados a facilitar la coherencia entre los objetivos de la política sectorial y entre la ordenación y la gestión.

\section{Las Estrategias y los inventarios nacionales.}

Para la aplicación de la gestión integrada en los Estados miembros y como paso previo para la elaboración de las "estrategias nacionales" la Recomendación propone -en su Capítulo $3^{\circ}$ - la creación de los llamados "inventarios nacionales" cuyo objetivo es "determinar los principales agentes, las normas y las instituciones que influyen en la gestión de las zonas costeras" y cuyos criterios deberían abordar los siguientes aspectos:

a) tener en cuenta (sin que se trate de una lista exhaustiva) los sectores y ámbitos siguientes:

- pesca y acuicultura,

- transportes,

- energía,

- gestión de recursos,

- protección de especies y hábitats,

- patrimonio cultural,

- empleo,

- desarrollo regional tanto en zonas rurales como urbanas,

- turismo y esparcimiento,

- industria y minas,

- gestión de los residuos,

- agricultura y

- educación;

b) abarcar todos los niveles administrativos;

c) analizar los intereses, cometido y preocupaciones de los ciudadanos, las organizaciones no gubernamentales y el sector empresarial;

d) determinar las organizaciones y estructuras de cooperación interregionales pertinentes, y 
e) consignar las políticas y medidas legislativas aplicables.

En cuanto a la elaboración de las "estrategias nacionales" que deben tener en cuenta los resultados de los “inventarios”, la Recomendación -en su Capítulo 4ㅜㅜ 1- deja en manos de los Estados la posibilidad de desarrollar una o varias estrategias nacionales de gestión integrada (en este caso se tratarían de estrategias regionales), siempre partiendo de la cooperación con las "autoridades regionales y las organizaciones interregionales". Asimismo deja libertad a los Estados para determinar si dichas estrategias han de referirse "específicamente a las zonas costeras" o pueden integrarse en "una estrategia o programa geográficamente más amplio para el fomento de la gestión integrada de una zona más extensa" (Capítulo $4^{\circ}, 2$ ). En todo caso, la Recomendación señala -en su Capítulo 4ำ 3- las determinaciones o contenidos mínimos que deberían contemplar las Estrategias, que son las siguientes:

a) definir las funciones respectivas de los distintos responsables administrativos del país o región cuyas competencias incluyan actividades o recursos relacionados con las zonas costeras y determinar los mecanismos para su coordinación. Esta definición de funciones debería garantizar una estrategia y un control adecuados y una coherencia de las actuaciones;

b) definir la combinación adecuada de instrumentos para la aplicación de los principios contemplados en el capítulo II, en el contexto jurídico y administrativo nacional, regional o local. Para la aplicación de las estrategias, los Estados miembros deberían decidir si conviene:

i) elaborar planes estratégicos nacionales para la costa a fin de fomentar la gestión integrada, garantizando entre otras cosas que se controle la urbanización adicional y la explotación de zonas no urbanas y que al mismo tiempo se respeten las características naturales del entorno costero.

ii) establecer mecanismos de compra de terrenos y de declaración de dominio público para garantizar el acceso público para fines de esparcimiento sin que ello afecte a la protección de las zonas sensibles,

iii) elaborar acuerdos voluntarios o contractuales con los usuarios de las zonas costeras, incluidos los acuerdos ambientales con el sector industrial,

iv) recurrir a incentivos económicos y fiscales, y

v) actuar aplicando los mecanismos de desarrollo regional;

c) desarrollar o mantener las normas o las políticas y programas nacionales, y en su caso regionales o locales, aplicables tanto a las zonas marinas como a las zonas terrestres de las costas;

d) en particular, determinar medidas para fomentar iniciativas ascendentes y la participación pública en materia de gestión integrada de las zonas costeras y de sus recursos;

e) determinar fuentes de financiación duraderas para las iniciativas en materia de gestión integrada de las zonas costeras cuando sea necesario, y estudiar cómo aprovechar de la mejor forma posible los mecanismos financieros existentes tanto a nivel comunitario como nacional; 
f) definir mecanismos para garantizar una aplicación íntegra y coordinada de la legislación y las políticas de la Comunidad que tengan incidencias en las zonas costeras, incluso a la hora de revisar las políticas comunitarias existentes;

g) incluir sistemas adecuados de control y de difusión de la información al público sobre sus zonas costeras. Estos sistemas deberían recoger y suministrar información en formatos adecuados y compatibles para los responsables locales, regionales y nacionales, con el fin de facilitar la gestión integrada. Entre otros podrán utilizarse como base a tal efecto los trabajos de la Agencia Europea del Medio Ambiente. Estos datos deben ser accesibles al público con arreglo a la legislación comunitaria aplicable, en particular la Directiva 2003/4/CE del Parlamento Europeo y del Consejo relativa al acceso del público a la información medioambiental;

h) determinar cómo unos programas nacionales de educación y formación adecuados pueden contribuir a la aplicación de los principios de la gestión integrada en las zonas costeras.

\section{La cooperación internacional y la ejecución de la Recomendación.}

Teniendo en cuenta que las estrategias sobre las zonas costeras pueden afectar a varios países, la Recomendación impulsa la cooperación y el dialogo entre los países vecinos (comunitarios o extracomunitarios) de un mismo mar regional con el fin de lograr una "mayor coordinación de las respuestas a problemas transfronterizos" (Capítulo 5ำ 1). Igualmente se recomienda que los Estados miembros trabajen en colaboración con las instituciones de la Comunidad Europea y otras partes interesadas en las zonas costeras para "garantizar los avances en la aplicación de un planteamiento común en materia de gestión integrada de las zonas costeras"; en esta misma línea se considera útil la creación de un "Foro europeo de partes interesadas en las zonas costeras" (Capítulo $\left.5^{0}, 2\right)^{15}$. Y ante la perspectiva de la adhesión de nuevos países a la Unión Europea se proponía, con el mismo fin, la cooperación con los países candidatos (Capítulo 5ํㅜ 3 ).

\footnotetext{
${ }^{15}$ Poco antes de la aprobación de la Recomendación 2002/413/CE de 30 de mayo, durante el mandato español en la Presidencia del Consejo y de la Comisión Europeo del semestre de enero a junio de 2002, se organizó entre el Gobierno español y la Comisión Europea el "I Foro Europeo sobre Gestión Integrada de las Zonas Costeras", que se celebró en el municipio de Villajoyosa (Alicante) entre los días 18 y 20 de abril de 2002. Se trataba de la primera vez en que los responsables políticos y técnicos de la gestión de las zonas costeras de los países de la Unión Europea y los países candidatos se reunían en un Foro de estas características para debatir e intercambiar experiencias sobre GIZC. Desde la reunión de Villajoyosa los Grupos de Expertos constituidos allí se han reunido en repetidas ocasiones para tratar de diferentes cuestiones relativas a la aplicación e interpretación de la Recomendación 2002/413/CE. Las reuniones han tenido lugar los días 3 de octubre de 2002, 18 de junio de 2003, 22 de abril y 24 de noviembre de 2004, 22 de septiembre de 2005, 1 de junio de 2006, 6 de marzo de 2007 y 27 de noviembre de 2008. Además de este Grupo de Expertos en GIZC se creó un Grupo de Trabajo sobre Indicadores y Datos (WG-ID) con el objetivo de definir un sistema de indicadores. Fruto de estas reuniones -desde la primera reunión (de 3 de octubre de 2002) en que se constituyó el grupo de expertos GIZC, hasta la última celebrada (de 27 de noviembre de 2008)- son varios documentos que tienen especial interés para resolver cuestiones que plantea la citada recomendación. Estos documentos pueden consultarse en la página web: http://ec.europa.eu/environment/iczm/home.htm (última consulta: 20 de mayo de 2010). En particular, se trata de los siguientes:

-de la segunda reunión celebrada el 18 de junio de 2003 resultaron los documentos que debían servir para elaborar los inventarios para información exigida por la Recomendación de 2002: el "Stocktaking Guidance" y la "Methodological Approach".

-el que lleva por título: “Measuring Sustainable Development on the Coast", con fecha de 2 de junio de 2003, en el que se recoge un sistema de indicadores ambientales necesarios para poder elaborar los estudios sobre el litoral exigidos por la Recomendación de 2002.

-también sobre indicadores el "Report of the Working Group on Indicators and Data to the EU ICZM Expert Group" fechado en Roterdam el 24 de noviembre de 2004.
} 


\section{$\operatorname{RerCED\varrho ̈̈UA~}$}

Por último, la Recomendación establece la obligación para los Estados miembros de informar a la Comisión "en el plazo de cuarenta y cinco meses" (es decir, antes de febrero del 2006) sobre las experiencias en la aplicación de la misma (Capítulo 60, 1). Dichos informes, que deberán hacerse públicos, deberán incluir -como dispone el Capítulo 6ํㅡ, 2-información sobre:

a) los resultados del inventario nacional;

b) la estrategia o estrategias propuestas a escala nacional para la aplicación de la gestión integrada de las zonas costeras;

c) un resumen de las medidas adoptadas, o que se vayan a adoptar, para aplicar la estrategia o estrategias nacionales;

d) una evaluación de los efectos previstos de la estrategia o estrategias sobre la situación de las zonas costeras;

e) una evaluación de la transposición y aplicación de la legislación y de las políticas comunitarias con repercusión en las zonas costeras.

Finalmente, la Comisión ha de revisar la Recomendación en el plazo de cincuenta y cinco meses (es decir, antes de enero del 2007) y presentar al Parlamento Europeo y al Consejo "un informe de evaluación acompañado, en su caso, de una propuesta de medidas comunitarias adicionales" (Capítulo 6으, 3).

\section{El Informe de la Comisión de 2007 de sobre la "evaluación de la gestión integrada de las zonas costeras en Europa".}

De acuerdo con lo previsto en el Capítulo Vl.3 de la Recomendación 2002/413/CE la Comisión presentó al Parlamento Europeo y al Consejo un informe de evaluación sobre la aplicación de la misma, plasmado en el documento COM(2007) 308 final, de 7 de junio de 2007. Para su preparación la Comisión ordenó el asesoramiento externo que fue realizado por Ruppercht Consult GmbH de Alemania y su socio el International Ocean Institute de Malta $^{16}$. También se tuvieron en cuenta para su elaboración un Informe de la Agencia Europea de Medio Ambiente publicado el 3 de julio de 2006 con el título: The changing faces of Europe's coastal areas $^{17}$ y otro Informe del Grupo de Trabajo sobre Indicadores y Datos

-con fecha de 22 de septiembre de 2005 se hizo público el documento "Guidance for the contents of Member States reports further to Chapter VI. 1-2 of the EU Integrated Coastal Zone Management (ICZM) Recommendation", a modo de guía para la elaboración de los informes de los Estados miembros en virtud de la Recomendación de 2002. -en noviembre de 2005, la Dirección General de Medio Ambiente publicó un documento sobre el “Progress in implementation EU ICZM Recommendation" en el que informaba sobre diversos datos relativos al proceso de ejecución de la Recomendación en todos los Estados miembros costeros.

-Un informe del Grupo de Trabajo sobre Indicadores y Datos (WG-ID), en el que se examina la utilización de indicadores en los informes nacionales en aplicación de la Recomendación GIZC UE: Report on the use of the ICZM indicators from the WG-ID, septiembre de 2006

${ }^{16}$ Dicho Informe, fechado el 18 de agosto de 2006 (y recibido por la Comisión el 1 de diciembre de 2006), que lleva por título Evaluation of Integrated Coastal Zone Management (ICZM) in Europe, puede consultarse en la página web: http://ec.europa.eu/environment/iczm/home.htm (última consulta: 20 de junio de 2010).

${ }^{17}$ Puede consultarse en su versión resumida (EEA Briefing 3/2006) en todas las lenguas oficiales de la Unión Europea en la página web: http://reports.eea.europa.eu/briefing_2006_3/en y en su versión completa (en inglés) en la página web: http://reports.eea.europa.eu/eea_report_2006_6/en/ (última consulta: 20 de mayo de 2010). En su versión resumida con el título "La degradación continuada de los litorales europeos amenaza el nivel de vida de los ciudadanos" se sintetiza el contenido del Informe del modo siguiente: "Vivir al lado del mar es muy atractivo. La gente percibe 
(WG-ID) relativo a la utilización de los indicadores utilizados en los informes nacionales de aplicación de la Recomendación de $2002^{18}$.

En su introducción, el documento sobre la evaluación de le Recomendación sitúa esta iniciativa en el marco de la "futura política marítima de la UE" que concluiría en la vigente Directiva 2008/56/CE por la que se establece un marco de acción comunitaria para la política del medio marino (también denominada "Directiva marco sobre la Estrategia Marina") ${ }^{19}$, a la que más adelante nos referiremos; también alude las posibles repercusiones de los efectos del cambio climático sobre las zonas costeras y a la política energética sostenible.

Tras analizar los antecedentes que dieron lugar a la aprobación de la Recomendación de 2002 - poniendo de relieve que "las zonas costeras son de importancia estratégica para la Unión Europea" y la necesidad de un enfoque más coherente e integrado de la ordenación y la gestión de las zonas costeras-, ilustra sobre la recepción de los informes nacionales sobre los progresos realizados por los Estados miembros costeros en la aplicación de la Recomendación ${ }^{20}$. De los 20 Estados miembros de la UE que tienen costa, 14 presentaron informes oficiales a la Comisión; esto representa el $65 \%$ de los Estados miembros costeros de la UE y más del $70 \%$ del litoral europeo ${ }^{21}$. Dentro de la lógica diversidad de situaciones entre los diferentes países y aun reconociendo que se han dado "avances hacia un enfoque más integrado de la ordenación y la gestión" se subraya que: "siguen siendo aún muy pocos los casos en que se observa una GIZC madura y realmente operativa en la que participen todos los niveles pertinentes de gobernanza".

Los resultados generales que arroja la evaluación de la Recomendación GIZC-UE no son muy optimistas: "La aplicación de la gestión integrada de las zonas costeras es un proceso lento ya largo plazo", "En la mayoría de los Estados miembros, la respuesta a la Recomendación GIZC UE forma parte de un proceso lento, pero constante, hacia una gestión y una ordenación costeras más integradas"; "Aunque sigue prevaleciendo el enfoque sectorial, las estrategias nacionales deberían proporcionar un marco más estratégico e integrado"; "la Comisión observa que los informes nacionales sobre la GIZC proporcionan pocos indicios de que existan mecanismos efectivos de aplicación"; etc. Sin embargo, también ha tenido efectos positivos: "ha tenido el efecto claro de fomentar la sensibilización e intensificar la actuación a favor de una ordena-

\footnotetext{
el litoral como un valor inmutable, pese a lo cual no dejan de ocasionarse daños y cambios irreversibles en los ecosistemas costeros. Las tendencias actuales revelan que los cambios en el uso del suelo en las zonas costeras superan a los observados en cualquier otro lugar; por ejemplo, el aumento de las superficies artificiales a lo largo de los litorales europeos se incrementa a un ritmo un tercio más elevado que en las zonas del interior.

Estos cambios están muy extendidos y son ocasionados por una variedad de factores (cambios demográficos, reestructuración económica, mayores niveles de vida, más tiempo de ocio y modelos de comercio mundial). En muchas regiones costeras estos factores han ocasionado transformaciones rápidas alterando de forma drástica la viabilidad potencial de los ecosistemas costeros a largo plazo y de los servicios que proporcionan. Es cada vez más probable que los impactos ya provocados en los ecosistemas costeros se vean exacerbados a partir de ahora por el cambio climático". Los subrayados son míos.

${ }^{18}$ Dicho Informe que lleva por título: Report on the use of the ICZM indicators from the WG-ID y está fechado en septiembre de 2006, puede consultarse en:

http://ec.europa.eu/environment/iczm/pdf/report_wgid.pdf (última consulta: 20 de mayo de 2010).

${ }^{19}$ cfr. DOUE L 164 de 25 de junio de 2008.

${ }^{20}$ Los citados informes nacionales pueden consultarse en la página web:

http://ec.europa.eu/environment/iczm/evaluation/iczm_national_reporting.htm (última consulta: 20 de mayo de 2010) ${ }^{21} \mathrm{~A} 31$ de diciembre de 2006 (que era cuando concluía el plazo de presentación), se habían recibido informes de los siguientes países: Alemania, Bélgica, Chipre, Dinamarca, España, Finlandia, Francia, Grecia, Letonia, Lituania, Malta, Países Bajos, Portugal y el Reino Unido. Se recibieron material preparatorio y otras contribuciones de Eslovenia, Polonia y Suecia. No se recibieron contribuciones nacionales de Estonia, Irlanda e Italia.
} 


\section{$\operatorname{RerCED\varrho ̈̈UA~}$}

ción y una gestión sostenibles de las zonas costeras..."; "La Recomendación GIZC UE sigue siendo válida como base para continuar apoyando estos procesos de integración. Puesto que la mayoría de los Estados miembros costeros ha respondido a la Recomendación GIZC UE...".

Pero, sin duda, el logro fundamental de la Recomendación ha sido, como dice la Comisión, "codificar un conjunto común de principios que debe sustentar una buena ordenación y gestión de las zonas costeras" 22 .

Como temas prioritarios que deben tratarse en las estrategias nacionales son los desafíos que derivan de los crecientes riesgos y posibles impactos del cambio climático ${ }^{23}$, necesitándose para ello "un planteamiento territorial coherente y transectorial"

Otra idea esencial es la siguiente: "Aunque la GIZC en la parte terrestre sigue siendo necesaria, habrá que hacer mayor hincapié en su aplicación a través de la frontera entre tierra y mar y en el contexto de los mares regionales...". Para la incidencia de la ordenación sobre los espacios marinos resulta particularmente valiosa la nueva perspectiva que-como veremos- abre la vigente Directiva Marco sobre la estrategia marina y las iniciativas que se vienen desarrollando en virtud de los Convenios sobre mares regionales (Mar Báltico, Atlántico Nordeste y Mediterráneo) ${ }^{25}$.

La invocación de la "buena gobernanza territorial" es otra constante de este documento y su relevancia es indiscutible en una estrategia como la de la gestión integrada del litoral en la mayoría de las políticas y los instrumentos de la UE tienen algún impacto en las zonas costeras. Y, por este motivo, la GIZC, por su carácter integral "ofrece un claro valor añadido" y "contribuiría a garantizar la coherencia entre políticas, planes y programas, y daría cabida y aplicación efectivas a planes y programas correspondientes a diferentes niveles de intervención". Aspectos todos ellos sobre los que también incide positivamente la futura política marítima de la UE.

La Comisión concluye el documento sobre la evaluación de la Recomendación de 2002 -además de considerar necesario proseguir los esfuerzos para apoyar la GIZC a nivel de la UE- ofreciendo varias orientaciones para el futuro que pasamos a sintetizar:

1ㅇ.-- se anima a los Estados costeros a aplicar sus estrategias de GIZC o a elaborarlas en los que todavía no se ha hecho, y en todo caso, "en colaboración con las partes interesadas pertinentes".

\footnotetext{
${ }^{22}$ No obstante, las diferencias en la interpretación de la GIZC en Europa exige que dichos principios deban ser -como dice la Comisión- más operativos y deben comunicarse mejor". También debe invertirse en sistemas más eficaces de intercambio de información y en la capacidad para analizarla y comunicarla a los responsables de la toma de decisiones y al público en general.

${ }^{23} \mathrm{Cfr}$. el segundo Programa Europeo de Cambio Climático (COM(2005) 35 de 9.2.2005), en particular su parte relativa a impactos y adaptación, y el Libro Verde propuesto sobre adaptación al cambio climático (2006/ENV/012, Programa legislativo y de trabajo de la Comisión para 2006, COM(2005) 531 final de 25.10.2005) son también de importancia clave para las zonas costeras de Europa.

${ }^{24}$ Este enfoque implica entre otras cosas que en las decisiones de ordenación e inversión se incorporen los riesgos relacionados con los posibles efectos del cambio climático.

${ }^{25}$ Cfr. las Decisiones 98/249/CE del Consejo, de 7 de octubre de 1997, relativa a la firma del Convenio sobre protección del medio marino del Nordeste Atlántico (Convenio de París) [Diario Oficial L 104 de 3.4.1998], 94/157/CE del Consejo, de 21 de febrero de 1994, relativa a la celebración en nombre de la Comunidad del Convenio sobre protección del medio marino de la zona del mar Báltico (Convenio de Helsinki revisado - 1992) [Diario Oficial L 73 de 16.3.1994] y 77/585/CEE del Consejo, de 25 de julio de 1977, relativa a la celebración del Convenio para la protección del mar Mediterráneo contra la contaminación, así como del Protocolo sobre la prevención de la contaminación del mar Mediterráneo causada por vertidos desde buques y aeronaves [Diario Oficial L 240 de 19.9.1977].
} 


\section{RerCEDöUA

2ํ.- se apela al conjunto de los Estados para lograr "una orientación que aclare los principios en los que se sustenta una buena ordenación y gestión de las zonas costeras y la manera de llevarlas a la práctica";

$3^{\circ}$-- se recomienda vivamente que las estrategias de GIZC se elaboren en "en estrecha coordinación y cooperación con la Directiva sobre estrategia marina y los Convenios relativos a los mares regionales" ya que son fundamentales para "configurar un planteamiento holístico del desarrollo sostenible de los océanos y los mares de la UE"

$4^{\circ}$.- - se destaca la importancia de la "coherencia entre los planes, los programas y la gestión que se ocupan respectivamente de las partes terrestre y marina de las zonas costeras", para lo cual, la repetida Directiva sobre la estrategia marina y los Convenios sobre mares regionales constituyen un instrumento imprescindible

$5^{0}$-. dada la gran vulnerabilidad de las zonas costeras a los riesgos y posibles impactos del cambio climático (y a otros peligros naturales o tecnológicos) se subraya la idea de que las estrategias de GIZC se adapten a estos riesgos.

6ํ․- por último, se recomienda seguir trabajando en la mejora de "los análisis comparativos y la comunicación y la promoción de buenas prácticas en relación con la GIZC, en concreto entre las regiones costeras", y en el desarrollo de "indicadores comunes y un marco para evaluar la eficacia y la eficiencia de la GIZC" ${ }^{26}$.

En cuanto al apoyo directo al proceso comunitario de la GIZC se identifican tres líneas de acción:

1o.- la política de cohesión europea, principalmente a través del objetivo de cooperación y de la iniciativa de las regiones.

$2^{2}$ - - la política común de la pesca mediante el Fondo Europeo de la Pesca que incluye un eje dedicado al desarrollo integrado y sostenible de la zonas dependientes de la pesca.

$3^{3}$.- la investigación que cuenta con la acción de coordinación ENCORA (relativa a la investigación y educación sobre las zonas costeras) puesta en marcha en 2006 con el apoyo de la UE.

En todo caso, es indiscutible, que pese a las muchas deficiencias observadas en la aplicación de la Recomendación de 2002, ha servido -como termina diciendo el Informe de la Comisión- "para fomentar el progreso hacia una ordenación y una gestión más integradas de las zonas costeras en Europa” y que "la actual Recomendación GIZC UE sigue siendo válida para apoyar la aplicación de las estrategias nacionales y promover la GIZC en todo el litoral europeo". Sin embargo, a nuestro juicio, el que la Recomendación de 2002 siga siendo válida no implica que sea el mejor instrumento ni el más eficaz para lograr los objetivos de la gestión integrada de las zonas costeras en Europa. Su naturaleza jurídica no vinculante (de soft law) constituye cierta rémora para la efectiva aplicación de instrumentos de ordenación y gestión en unas zonas costeras de Europa necesitadas con urgencia de la perspectiva integrada y holística que orienta la política de la GIZC.

\footnotetext{
${ }^{26}$ Cfr. el trabajo de PICKAVER, A. H., GILBERT, C., BRETO. F.: "An indicator set to measure the progress in the implementation of integrated coastal zone management in Europe”, Ocean and Coastal Management, № 47 (2004), pp. 449-462.
} 


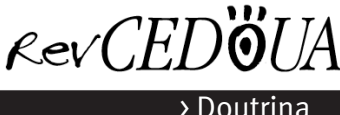

\section{Breve Referencia a la Directiva Marco del Agua y a su Incidencia sobre las Zonas Costeras}

Una de las novedades más significativas de la Directiva Marco del Agua 2000/60/CE es la incorporación de las 'aguas costeras' y ‘aguas de transición' en la gestión unitaria e integrada del ciclo hidrológico. El calendario de implantación de la Directiva prevé que a finales del año 2009 esté finalizada la elaboración de los programas de medidas y los nuevos Planes Hidrológicos de cuenca, en los que ha de reflejarse la necesaria integración protectora de las aguas continentales, en transición y costeras.

Poner de relieve la necesidad de integración de las aguas continentales y marinas en la ordenación, gestión y planificación es la primera conclusión que ha de extraerse de la nueva política ambiental comunitaria, basada en la "gestión de acuerdo con la naturaleza propia de los ecosistemas" (ecosystem-based Management).

Entre los instrumentos de protección del medio ambiente acuático no cabe duda de que la planificación ocupa un lugar primordial. Con ocasión de la preparación de los nuevos 'Planes hidrológicos de las cuencas' en el horizonte del 2009 parece muy oportuna la reflexión sobre todos los aspectos relativos a la interrelación entre la planificación hidrológica, la costera, la territorial y la ambiental para lograr una ordenación integrada de los recursos naturales en su conjunto.

Además de la necesaria coordinación y colaboración entre las diferentes Administraciones Públicas concurrentes sobre el medio acuático -marino y continental-, los futuros planes hidrológicos constituyen un instrumento de primera magnitud para lograr una protección integrada y sostenible de los recursos acuáticos. Dichos planes han de ampliar sus objetivos y su ámbito de actuación que ya no se limita al tradicional "dominio público hidrológico". Por otra parte, el control ambiental al que deben someterse los planes hidrológicos mediante el mecanismo de la "evaluación ambiental estratégica" permitirá garantizar su orientación holística.

Por último, planificación integrada de las zonas costeras debe de tenerse en cuenta igualmente los contenidos y exigencias de la Directiva 2007/60/CE del Parlamento y del Consejo de 23 de octubre de 2007, relativa a la evaluación y gestión de los riesgos de inundación. Hace una referencia expresa a las zonas costeras (cfr. arts. 2,1; 3,2,b); 4,2,a); 6,6; 13,1), permite establecer cuencas hidrográficas distintas de las previstas por la Directiva Marco y designar autoridades competentes diferentes, y establece los plazos, le proceso de elaboración de los "planes de gestión de riesgo de inundación", así como el programa de medidas para incorporar en la revisión de la Directiva Marco en 2015.

\section{La gestión integrada del litoral en el marco de la nueva política marítima de la unión europea y la directiva marco sobre estrategia marina de $2008^{27}$.}

\section{Precedentes}

Un hito de enorme importancia para el desarrollo del proceso de gestión integrada de las zonas costeras -fomentado por las instituciones comunitarias a través de la repetida Recomendación 2002/413/CE- es la puesta en marcha de la política marítima de la Unión Europea que acaba de culminar con la aprobación de la Directiva 2008/56/CE por la que se establece un marco de acción comunitaria para la política del medio marino (Directiva marco sobre la Estrategia Marina). La Unión Europea ha seguido en este punto las estrategias e iniciativas que se han 


\section{$\operatorname{RerCEDöUA~}$

dado en varios paises desarrollados (principalmente en el mundo anglosajón) ante la preocupación por la degradación ambiental de los océanos, mares y zonas costeras ${ }^{28}$.

La nueva Directiva se encuadra en el marco de lo que se viene denominando "política marítima de la Unión Europea" y en cuya gestación han contribuido varias iniciativas de la Comisión Europea. Así, de forma sintética:

1‥- la Comunicación de la Comisión al Consejo y al Parlamento Europeo que, fechada en Bruselas el 2 de octubre de 2002, lleva por título: Hacia una estrategia de protección y conservación del medio ambiente marino (COM (2002) 539 final), en la que se pone de manifiesto la necesidad de abordar el objetivo global destacado en el 6 o Programa comunitario de acción en materia de medio ambiente: "promover la utilización sostenible de los mares y proteger los ecosistemas marinos".

2 - - la adopción por la Comisión, en octubre de 2005, de la Estrategia temática sobre la protección y la conservación del medio ambiente marino, que incluía una propuesta de Directiva sobre la estrategia marina ${ }^{29}$. Partiendo de la gran importancia que tiene para Europa la economía marítima y teniendo en cuenta asimismo la importancia y la vulnerabilidad y deterioro de los ecosistemas marinos europeos, la Comisión anuncia la configuración inicial de una nueva política marítima de la Unión Europea.

$3^{3}$.- El Libro Verde titulado Hacia una política marítima de la UE: perspectiva europea de los océanos y los mares $^{30}$ presentado por la Comisión Europea, en junio de 2006, que constituye la respuesta a sus objetivos estratégicos par 2005-2009 y se basa en la estudiada Comunicación de 2 de marzo de $2005^{31}$. El Libro Verde destaca la identidad y supremacía marítima de Europa, que es necesario preservar en un periodo en el que las presiones ambientales amenazan la pervivencia de actividades marítimas. Así pues, la política marítima debe plantearse una industria marítima innovadora, competitiva y respetuosa con el medio ambiente. Además de las actividades marítimas (transporte, turismo, energía, construcción naval, etc.), el enfoque propuesto integra también la calidad de vida de las regiones costeras. El Libro Verde se plantea a este respecto el desarrollo de nuevos instrumentos y métodos de buen gobierno marítimo. Entre las

\footnotetext{
${ }^{27}$ Un estudio mas exhaustivo de este tema puede encontrarse en el trabajo de SANZ LARRUGA, F. J.: "La Unión Europea y la Estrategia comunitaria sobre gestión integrada de las zonas costeras", en SANZ LARRUGA, F.J. (Dir.) y GARCÍA PÉREZ, M. (Coord.): Estudios sobre la ordenación, planificación y gestión de litoral: Hacia un modelo integrado y sostenible, Fundación Pedro Barrié de la Maza y Observatorio del Litoral de la Universidad de A Coruña, A Coruña, 2009, pp. 45-48.

${ }^{28}$ Así, por ejemplo, el caso de Australia (Oceans Policy de 1998 y Commonwealth Coastal Policy de 1995), de Canadá (Oceans Action Plan de 2004) y de los Estados Unidos (la Oceans Act de 2000 y el Ocean Blueprint for the 21st century elaborado por la Comisión de los Estados Unidos sobre Política Marina y publicado en 2004). Recientemente la Administración del Presidente OBAMA ha publicado -en abril de 2009- un documento titulado Changing Oceans, changing world en el que se contienen las prioridades del Gobierno sobre la protección de los océanos y de las zonas costeras.

${ }^{29} \mathrm{Cfr}$. los documentos de la Comunicación de la Comisión al Consejo y al Parlamento Europeo: COM(2005) 504 y 505 de 14 de octubre de 2005. Cfr. el trabajo de JUDA, L.: "The European Union and Ocean Use Management: the Marine Strategy and the Maritime Policy", Ocean Development and International Law, n으 38 (2007), pp. 259-282. ${ }^{30} \mathrm{Cfr}$. los siguientes documentos: la Comunicación de la Comisión al Consejo, al Parlamento Europeo, al Comité Económico y Social Europeo y al Comité de las Regiones titulado "Hacia una política marítima de la Unión Europea: Perspectiva europea de los océanos y los mares" (COM(2006) 275 final, Volumen I, fechado en Bruselas el 7 de junio de 2006 y su Volumen II que a modo de Anexo (y con la misma referencia COM) recoge una frase atribuida a A. C. CLARKE: "Cuán inadecuado es llamar Tierra a este planeta, cuando es evidente que debería llamarse "océano". ${ }^{31} \mathrm{Cfr}$. el trabajo de SUÁREZ DE VIVERO, J. L.: "The European vision for oceans and seas- social and political dimensions o the Green Paper on Maritime Policy for the EU”, Marine Policy, nํㅜ 31 (2007), pp. 409-414.
} 
cuestiones que se plantean en el Libro Verde de cara a la consulta pública tiene especial importancia a los efectos de este trabajo el apartado 3 titulado "Mejorando la calidad de vida en las regiones costeras" ${ }^{32}$.

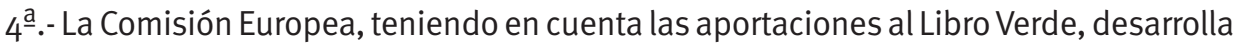
en su Comunicación de 10 de octubre de 2007 "una política marítima integrada para la Unión Europea" (The Blue Book) ${ }^{33}$. La clave de esta política descansa en "el reconocimiento claro de la interconexión de todo lo relativo a los océanos y mares europeos y de que las políticas relacionadas con el mar deben formularse conjuntamente para poder obtener los resultados perseguidos" ${ }^{34}$. En junio de 2008, la Comisión publicó una Comunicación titulada "Orientaciones para un planteamiento integrado de la política marítima: hacia mejores prácticas de gobernanza marítima integrada y consulta de las partes interesadas" ${ }^{35}$. Estas orientaciones propuestas por la Comisión están destinadas a orientar la acción de los actores públicos y privados en la elaboración de sus respectivas políticas marítimas nacionales ${ }^{36}$.

\section{La Directiva Marco sobre Estrategia Marítima y la GIZC.}

La Directiva 2008/56/CE por la que se establece un marco de acción comunitaria para la política del medio marino (también denominada “Directiva marco sobre la Estrategia Marina") determina los principios comunes sobre cuya base los Estados miembros deberán elaborar, en colaboración con los Estados miembros y terceros Estados, sus propias estrategias para alcanzar un estado ecológico satisfactorio de las aguas marinas de las que sean responsables ${ }^{38}$.

\footnotetext{
${ }^{2}$ De su contenido destacamos los siguientes aspectos:

$1^{\circ}$ ) se pone de manifiesto el "creciente atractivo de las zonas costeras como lugares de residencia y de trabajo", lo cual implica que el desarrollo de estas actividades conlleva "presiones inevitables sobre el espacio y el medio ambiente".

$\left.2^{\circ}\right)$ se incide en la necesidad de adaptar o proteger las zonas costeras frente a los riesgos potenciales, tanto los antropogénicos (contaminación accidental y operacional, migraciones ilegales, terrorismo, etc.) como los naturales (catástrofes naturales, cambio climático, erosión costera, inundaciones, maremotos, etc.) que inciden sobre el litoral, obligando a aportar las respuestas adecuadas en cada caso.

$3^{0}$ ) se destaca el desarrollo del turismo costero en Europa que lo convierte en la región turística más importante del mundo y las presiones derivadas de esta actividad deben de minimizarse mediante el "turismo sostenible" que puede contribuir al desarrollo de las zonas costeras y las islas.

$4^{\circ}$ ) En el apartado 3.4 del Libro Verde se hace referencia a la necesidad de gestionar adecuadamente el "interfaz mar/tierra".

${ }^{33}$ Cfr. la Comunicación de la Comisión al Parlamento Europeo, al Consejo, al Comité Económico y Social y al Comité de las Regiones, COM(2007) 575 final, fechado en Bruselas el 10 de octubre de 2007. Vid. asimismo, en documento de trabajo de los servicios de la Comisión adjunto al anterior con el resumen de la evaluación de impacto (SEC(2007) 1280)

${ }^{34}$ El documento identifica entre los instrumentos de la política integrada el relativo a la "ordenación marítima y gestión integrada de las zonas costeras". Por otra parte, la ordenación marítima se califica como "una herramienta fundamental para el desarrollo sostenible de las zonas costeras, así como pare el saneamiento ambiental de los mares de Europa”. ${ }^{35}$ Comunicación de la Comisión al Consejo, al Parlamento Europeo, al Comité Económico y Social y al Comité de las Regiones, de 26 de junio de 2008 (COM(2008) 395 final). La elaboración de la política marítima integrada es uno de los objetivos estratégicos de la Comisión para el periodo 2005-2009.

${ }^{36}$ Por lo que se refiere a las zonas costeras la Comisión considera que las regiones costeras y otros responsables de las decisiones locales deberían poder desempeñar un papel en la elaboración de las políticas marítimas integradas, dada su experiencia en materia de gestión integrada de las zonas costeras y de reglamentación de la ordenación territorial de sus actividades.

${ }^{37}$ DOUE, L 164, pp. 19-40 de 25 de junio de 2008. Cfr. el trabajo de BORJA, A.: “The new European Marine Strategy Directive: difficulties, opportunities, and challenges”, Marine Pollution Bulletin. United Kingdom. № 52, 3. (2006), pp 239-242.

${ }^{38}$ En el caso de España, con fecha de 27 de julio de 2009, se divulgó por el Ministerio de Medio Ambiente y Medio Rural y Marino el anteproyecto de "Ley de Protección del Medio Marino" que, fundamentalmente, pretende responder a la transposición en España de la Directiva 2008/56/CE; actualmente se está tramitando como Proyecto de Ley en el Parlamento español.
} 


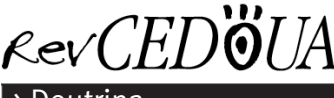

Estas estrategias tienen como objetivo proteger y restablecer los ecosistemas marinos europeos, y garantizar la viabilidad ecológica de las actividades económicas relacionadas con el medio marino de aquí al año 2021.

Las aguas marinas europeas se dividen en cuatro regiones (con subregiones, si procede): el mar Báltico, el océano Atlántico Nororiental, el mar Mediterráneo y el mar Negro. En cada región y posibles subregiones a que pertenezcan, los Estados miembros interesados deberán coordinar su acción, entre sí y con los terceros Estados interesados. Para ello podrán recurrir a la experiencia y eficacia de las organizaciones regionales.

En cuanto a la estrategias marinas a escala regional: en primer lugar, los Estados deberán evaluar el estado ecológico de sus aguas y el impacto de las actividades humanas. Esa evaluación incluirá: un análisis de las características esenciales de esas aguas (especificidades físicas y químicas, tipos de hábitat, poblaciones animales y vegetales, etc.); un análisis de los principales impactos y presiones, especialmente debidos a las actividades humanas que influyen en las características de esas aguas (contaminación por productos tóxicos, eutrofización, asfixia o sellado de los hábitats por construcciones, introducción de especies no autóctonas, daños físicos por las anclas de los buques, etc.); un análisis económico y social de la utilización de esas aguas y del coste del deterioro del medio marino.

A continuación, los Estados han de determinar el «estado ecológico satisfactorio» de las aguas teniendo en cuenta, por ejemplo, la diversidad biológica, la presencia de especies alóctonas, la salud de las reservas, la red trófica, la eutrofización, la modificación de las condiciones hidrográficas y la concentración de contaminantes, la cantidad de residuos o la contaminación acústica.

En función de la evaluación de las aguas, los Estados definirán objetivos e indicadores para alcanzar el estado ecológico satisfactorio. Dichos objetivos deberán ser mensurables, coherentes dentro de una misma región o subregión marítima, y estarán sujetos a un plazo de realización.

Los Estados establecerán un programa de medidas concretas para alcanzar esos objetivos. Dichas medidas deberán elaborarse teniendo en cuenta sus consecuencias económicas y sociales. Los Estados deberán especificar las razones que impidan la realización de algunas de esas medidas (acción u omisión de otro Estado, fuerza mayor, etc.). Antes de su aplicación, las medidas adoptadas por los Estados deberán ser objeto de estudios de impacto y de análisis de costes y beneficios. Los Estados deberán elaborar asimismo programas de control coordinados para evaluar periódicamente el estado de las aguas de las que sean responsables y el cumplimiento de los objetivos que hayan definido. Los elementos de las estrategias se reexaminan cada seis años y se redactarán informes intermedios cada tres años.

Resulta indudable que la nueva Directiva sobre la Estrategia Marina constituye un espaldarazo para el proceso de gestión integrada de las zonas costeras. Sus objetivos son concurrentes y participan de la misma perspectiva holística e integrada de cuantas actividades y acciones inciden sobre el litoral. Frente a la naturaleza jurídica no vinculante de la Recomendación de 2002, la Directiva Marina es vinculante para los Estados miembros que, como establece el art. 26, 1 de la misma, deberán transponerla a sus ordenamientos internos antes del 15 de julio de 2010. Bien es verdad, no obstante, que los objetivos de la Directiva se proyectan a muy largo plazo, en definitiva, "adoptar medidas necesarias para lograr o mantener un buen estado medioambiental del medio marino a más tardar en el año 2020” (art. 1, 1). 
Tanto en las "Estrategias" que deben adoptar -en virtud del art. 5 de la Directiva- los Estados costeros antes del 15 de julio de 2012 (con la consiguiente evaluación inicial y la definición del buen estado medioambiental de las aguas marítimas, además de los objetivos medioambientales e indicadores asociados), como el "programa de seguimiento" (elaborado y aplicable antes del 15 de julio de 2014) y los "programas de medidas" destinado a alcanzar o mantener dicho estado medioambiental (para el 2015) sólo podrán alcanzarse si se ha puesto en marcha el proceso de gestión integrada del litoral.

\section{Reflexiones Finales.}

La Recomendación 2002/413/CE es ciertamente una acto comunitario de soft law, sin carácter vinculante. Pero, a mi juicio, la gestión del litoral de acuerdo con la lógica de los ecosistemas, la necesaria coordinación entre las Administraciones Públicas con competencias concurrentes, la obligada participación de los actores sociales y económicos en los procesos de protección y transformación de las zonas costeras, el acceso a la información sobre el estado de los ecosistemas costeros, la preservación de los derechos de las generaciones venideras, la utilización racional de los recursos naturales, etc. son todas ellas ideas-fuerza del proceso que debe seguir las políticas públicas del futuro sobre el litoral si no se quiere acabar con tan rico patrimonio natural de la humanidad.

Si desde la perspectiva terrestre se han venido diseñando las soluciones estratégicas para la protección del litoral (a través de variados instrumentos de ordenación del territorio y políticas urbanísticas) aunque con escasos resultados, en los últimos años son las estrategias de protección del medio marino (de protección de los océanos, los mares y las costas) las que están abriendo unas nuevas y esperanzadoras perspectivas de ordenación de la costa. Y en esta dirección se encamina la nueva Directiva 2008/56/CE que los Estados deberán transponer a sus ordenamientos, y por esta vía se deberán aplicar la metodología y los criterios de la gestión integrada de las zonas costeras ya que, como hemos visto, ésta constituye uno de las piezas claves de la naciente política marítima de la Unión Europea.

En definitiva, convencidos de la importancia de los objetivos que se propone la Recomendación 2002/413/CE y mediante la implantación de la nueva normativa comunitaria sobre la política marítima y costera, Portugal - como el resto de los Estados costeros de la Unión Europea - está obligado a implantar, tarde o temprano, el nuevo paradigma de gestión integrada de las zonas costeras, durante mucho tiempo relegado al campo de la discusión doctrinal.

Dr. Francisco Javier Sanz Larruga

Profesor Titular de Derecho Administrativo Director del Observatorio del Litoral UNIVERSIDAD DE A CORUÑA (España)
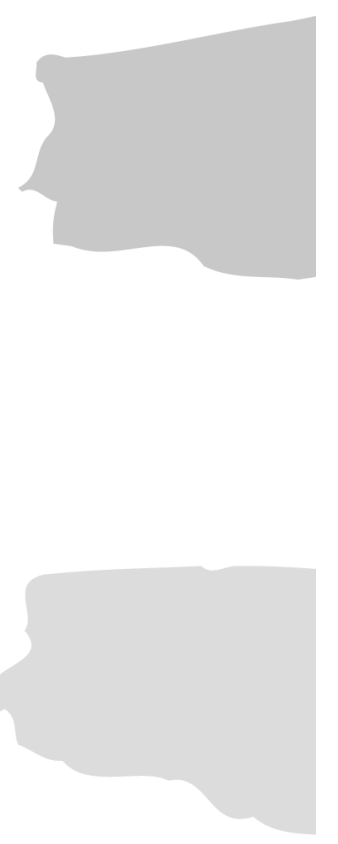


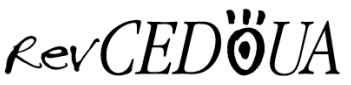

\section{Bibliografía}

ALVES, M.F.L.: Gestão sustetável das Zonas Costeiras. Contributos para um modelo de avaliaçao, Tesis doctoral em Ciências Aplicadas al Ambiente, Universidade de Aveiro, 2005;

ALVES CORREIA, F.: “Líneas generales de la ordenación y gestión de la zona costera en Portugal”, en SANZ LARRUGA, F.J. (Dir.) y GARCÍA PÉREZ, M. (Coord.): Estudios sobre la ordenación, planificación y gestión de litoral: Hacia un modelo integrado y sostenible, cit. pp. 69-80.

BARRAGÁN MUÑOZ, J.M.: Ordenación, planificación y gestión del espacio litoral, Oikos-tau, Barcelona, 1993.

BARRAGÁN MÚÑOZ, J. M. Las áreas litorales de España. Del análisis geográfico a la gestión integrada. Editorial Ariel, Barcelona, 2004.

BARRAGÁN MUÑOZ, J. M.: Política y gestión de áreas litorales en España, La gestión de áreas litorales en España y Latinoamérica, Universidad de Cádiz, Cádiz, 2005.

BORJA, A.: "The new European Marine Strategy Directive: difficulties, opportunities, and challenges", Marine Pollution Bulletin. United Kingdom. № 52, 3. (2006), pp 239-242.

CALERO RODRIGUEZ, J. R.: Régimen jurídico de las costas españolas, Aranzadi, Pamplona, 1995.

COMISIÓN EUROPEA: Hacia una estrategia europea para la gestión integrada de las zonas costeras: principios generales y opciones políticas, Oficina de Publicaciones de la Comunidad Europea, Luxemburgo, 1999.

COMISIÓN EUROPEA: La Unión Europea apuesta por las zonas costeras, Comunidades Europeas, Luxemburgo, 2001

COMISIÓN EUROPEA: Lecciones del programa de demostración de la Comisión Europea sobre la gestión integrada de las zonas costeras, Oficina de Publicaciones de la Comunidad Europea, Luxemburgo, 1999.

COMISIÓN EUROPEA: Vivir con la erosión costera en Europa. Sedimentos y espacio para la sostenibilidad. Resultados de Estudio Eurosion, 2004.

EUROPEAN ENVIRONMENT AGENCY: Europe's Environment: The Second Assessment, Office for Oficial Publications of the European Communities, Luxembourg, 1998.

FUENTES BODELÓN, F.: Calidad de vida, medio ambiente y ordenación del territorio. Textos internacionales, I, CEOTMA-CIFCA, Madrid, 1982.

GIBSON, J.: Legal and regulatory bodies: appropiateness to Integrated Coastal Zone Management, Comisión Europea, octubre de 1999

HERRERA XIMENEZ, M. D.: “La gestión costera en los Estados Unidos: Coastal Zone Management Act, 1972 y la estructura del programa asociado Coastal Zone Management Program", en SANZ LARRUGA, F.J. (Dir.) y GARCÍA PÉREZ, M. (Coord.): Estudios sobre la ordenación, planificación y gestión de litoral: Hacia un modelo integrado y sostenible, Fundación Pedro Barrié de la Maza y Observatorio del Litoral de la Universidad de A Coruña, A Coruña, 2009, pp. 81-90.

JUDA, L.: "The European Union and Ocean Use Management: the Marine Strategy and the Maritime Policy", Ocean Development and International Law, no 38 (2007), pp. 259-282.

MARTINS, F.M.: Políticas de Planeamento, Ordenamento e Gestao Costeira. Contributo para uma discussao metodológica, Tesis doctoral. Departamento de Ambiente e Ordenamento. Universidade de Aveiro, Aveiro, 1997;

MORENO CANOVÉS, A.: Régimen jurídico del litoral, Tecnos, Madrid, 1990.

ORGANIZACIÓN DE COOPERACIÓN Y DESARROLLO ECONÓMICOS: Gestión de zonas costeras. Políticas integradas, OCDE-Ediciones MundiPrensa, Madrid, 1995 


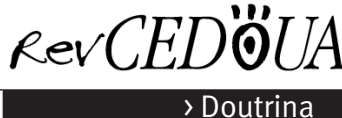

PÉREZ CONEJO, L.: Las costas marítimas: régimen jurídico y competencias administrativas, Comares, Granada, 1999.

PICKAVER, A.H., GILBERT, C., BRETO. F.: "An indicator set to measure the progress in the implementation of integrated coastal zone management in Europe", Ocean and Coastal Management, № 47 (2004), pp. 449-462.

PRIEUR, M.: “Integrated coastal zone management law”, en Umweltrecht, Festschrift für Eckard Rebhinder, Erich Scmidt Verlag, Berlin (2007) pp. 492-519

PRIEUR, M.: “La gestion intégrée des zones côtières”, en Environmental policy and law, Vol 37, n 2-3, march 2007, Amsterdam, pp.170-175

SANZ LARRUGA, F. J.: “La Unión Europea y la Estrategia sobre Gestión Integrada y sostenible del litoral”, Noticias de la Unión Europea, no 217 (2003), pp. 117-132.

SANZ LARRUGA, F.J.: "La Unión Europea y la estrategia comunitaria sobre gestión integrada de las zonas costeras", en SANZ LARRUGA, F.J. (Dir.) y GARCÍA PÉREZ, M. (Coord.): Estudios sobre la ordenación, planificación y gestión de litoral: Hacia un modelo integrado y sostenible, Fundación Pedro Barrié de la Maza y Observatorio del Litoral de la Universidad de A Coruña, A Coruña, 2009, pp. 29-54.

SCIBERRAS, A. M.: "Integrated Coastal Zone Management. A challenge for the EU in the 21st Century", Eipascope 2002/1, pp. 25-29 (se puede consultar en la siguiente dirección: http://www.eipa.nl)

SUÁREZ DE VIVERO, J. L.: “La ordenación del litoral en Europa: políticas nacionales y estrategias comunitarias”, en Revista Geográfica, 31 (1993), pp. 124-128.

SUÁREZ DE VIVERO, J. L.: “The European vision for oceans and seas- social and political dimensions o the Green Paper on Maritime Policy for the EU”, Marine Policy, no 31 (2007), pp. 409-414.

TROS-DE-ILARDUYA FERNÁNDEZ, M.: "El reto de la gestión integrada de las zonas costeras (GIZC) en la Unión Europea”, en Boletín de la A.G.E., no 47 (2008), pp. 143-156.

VELOSO GOMES, F. (COORD.): Bases para a Estratégica da Gestão Integrada da Zona Costeira Nacional, Projecto de Relatório do Grupo de Trabalho, Ministerio de Ambiente, do Ordenamento do Territorio e do Desenvolvimiento Regional, 23 de janeiro de 2006, 2006.

VILLANUEVA CUEVAS, A.: La regulación jurídica del litoral costero en Estados Unidos, Editorial Alfonsipolis, C.B. 2006. 